\title{
The revival of an ancestral galenic preparation called "Ceratum" apt to re-establish the normal viscoelasticity of dermis in perilous skin diseases like iatrogenic dyshidrosis and to treat scars after milia removal.
}

\author{
Texia Research ${ }^{1}$, Lorenzo Martini² \\ ${ }^{1}$ Texia Research-Eu-TURIN, ${ }^{2}$ Department of Pharmaceutical Biotechnologies University of Siena
}

\begin{abstract}
Scope of our research is to paving the way for a revival of a very old galenic preparation, that is nort oily or waxy, and so it cannot be baptized as ointment or unguentum. But the Trojan horse is that medical device I ideated (and its modus operandi is quite difficult and artful) is capable to re-establish an optimal viscoelasticity to dermal component of human skin and moisture at niveau of the stratum corneum in pathological cases that are rare and commonly impossible to be treated, as iatrogenic dyshidrosis and the suppurative state of skin when eruptive milia are removed physically from skin in order to obtain a restitutio ad integrum that is perfect and absolutely free from anomalies.
\end{abstract}

Keywords: Ceratum, iatrogenic dyshidrosis, eruptive milia, Rombo syndrome, ballistometer.

\section{Background}

Ceratum is an ancient term to indicate a sort of ointment capable to strongly adhere to epidermis and create a viscous but resistant film upon the stratum corneum slowly and progressively, permitting to all the ingredients that are inserted in formula to penetrate deeply and regularly through the skin at all.

For example an old U.S.P. refers about the Ceratum Juniperi Virginiani and the Ceratum Resinosus, a supplement of a British Pharmacopoeia by Samuel Frederick Gray, 1821, records the Ceratum citrinum and the Ceratum cerae et resinae flavae, in the Pharmacopoeia Collegii Regalis Medicorum Londinensis (1824), the Ceratum Sabinae, the Ceratum saponis, the Ceratum resinae (yclept Yellow Basilicon), the Ceratum Plumbi compositum, the Ceratum Plumbi acetati, the Ceratum calaminae yclept Epulotic Cerate and the Cerate of Spanish fly.The Mexican Pharmacopoeia of 1885 refers about the Ceratum cosmeticum anglicum e centuries of other cerates that are to be recorded in the Annals of History.

All cerates were prepared melting yellow wax and stirring slowly cold olive oil and all the other ingredients to obtain the appropriate Ceratum.

I have created a modern ceratum, based on the same ancestral method of proceeding, using white wax, because present a lower melting point and jojoba wax, besides squalane, ceramides and shea butter.

The innovation of this revisited ceratum is the Jojoba oil, that is considered as chief ingredient and not an emollient: jojoba oil contains the $76 \%$ of 11 -eicosanoic acid, a monoinsaturad fatty acid $(20 \mathrm{C})$ that is responsible of creating the flexible and strong barrier upon the stratum corneum, so that the aqueous vapour cannot poor out absolutely.

By this way, even if the patient spreads the Ceratum in a cold and dry day, all the wetness inside his dermis remains at intracellular niveau, and if he spreads it during a wet and hot day, the lypophilic layer impedes the pooring out of all hydrosoluble elements from inside.

Ceratum is dedicated most of all to all types of iatrogenic skin disydrosis and is suggested after the removal of eruptive milia expecially in childhood, in order to avoid they could become cysts and/or remain as connotation signals on face for all life.

Iatrogenic skin dyshidrosis is often evoked by long term therapies that are used to combat several malaises or by physical methods for diagnose other diseases or cure or after surgical operations, and so, for instance, among the dyshidrosis caused by prolonged use and abuse of medicaments, manifolds medications against Folate deficiency, thalaxemia, Hyperglycemia, Nelson syndrome/ACTH secreting,(1)lichen planus, dermatitis herpetiformis, erythema multiforme, pompholyx, autoimmune progesterone dyshidrosis, induced pemphigus/penicillamine xerosys, Dumping Syndrome,(2) Chronic dysentery, Bacterial folliculitis, Fibrositis and finally abuse of antidepressants; among the physical methods of diagnose the Radiation/ionizing/xray and among the post surgical operations the bilateral adrenalectomy and sometimes after some types of traumatic situations.

Milia, on the other hand, are benign, keratinous cysts that commonly manifest as tiny white bumps on the face of the newborn. When present on the gum margin, they are referred to as Bohn'spots. Milia can be broadly categorized into primary and secondary types. Congenital milia in newborns account for the vast 
The revival of an ancestral galenic preparation called "Ceratum" apt to re-establish the normal ..

majority of primary milia. Primary milia may also occur in association with one of several genodermatoses or sporadically without associated findings. Secondary milia may be associated with an underlying skin disease, medications, or trauma.

Berk and Bayliss published an updated classification of milia, as follows (3)

Primary milia may be:

Congenital, Benign primary milia of children and adults, Milia en plaque ,Nodular grouped milia, Multiple eruptive milia ,Nevus depigmentosus with milia, genodermatosis.

Secondary milia are often associated to abuse of medications or post-traumatic conditions.

Benign acquired milia of children and adults also occur spontaneously; however, like other acquired milia, they have a tendency to persist without treatment. Benign acquired milia of children and adults favor the eyelids, cheeks, forehead and genitalia.

Multiple eruptive milia describes acquired and widespread milia that appear rather abruptly over weeks to months. Multiple eruptive milia may be associated with a genodermatosis or inherited in an autosomal dominant fashion without other apparent anomalies; however, in most cases they occur sporadically.

Genodermatosis-associated milia have been reported in association with basal cell nevus syndrome, (4) Rombo syndrome, (5) Brooke-Spiegler syndrome, (6) pachyonychia congenita type 2, (7)and atrichia with papular lesions. (8)

In children, traumatic milia most commonly manifest following abrasions or burns. Milia have also been reported following skin grafting. Milia may occur in association with blistering skin diseases. Epidermolysis bullosa and porphyria cutanea tarda are the classic examples. Milia associated with topical corticosteroid use is rarely reported. (9)

The most common type of milia removal is performed using a needle. Once the skin with milia has been cleaned, a sterile needle is then used to create an tiny incision in the skin covering the cyst and the contents of the milia are carefully extracted so as not to cause any trauma to the skin.

Certain types of milia may not be suitable for this type of removal, and may need to be treated using a hyfrecator. A hyfrecator works to cauterize the skin covering the milia by using tiny electrical pulses then allowing the contents to be extracted.

In other cases it may be more suitable to be prescribed a topical medication to treat the milia, but this is only for certain types of milia, especially the eruptive ones and nodular grouped milia.(10-11)

The best treatment will depend upon the type of milia as well as the location and number of milia that need to be removed.Beauticians suggest treatments by using a non-abrasive exfoliating cleanser and vitamin A product on a regular basis. Milia tend generally to recur, after gentle microabrasion. These products will soften the skin that covers the milia, making it easier to remove and can also help prevent further milia developing.

After the removing of milia, the upper three layers of epidermis are injured, and the risk of a misleading cicatrisation (almost at the very first step, the inflammatory one, when tissues may undergo bacterial assaults) is to be exorcised.

For this, I created a Ceratum, apt to create a sort of thick waxy film, that owing to its lypophily tends to suffocate all bacteria Gram positive and Gram negative.

\section{Materials and methods}

We have recruited 4 (four) volunteers who willingly made up their mind to undergo our experimentations for nine (9) days and we have used a ballistometer (Dia-Strom torsional ballistometer) to evaluate the increase of the hydration and degree of viscoelasticity of their skin and derma.

The individuals were:

1) one middle age woman suffering from Saurat-Kaya's syndrome.the clinical manifestations of the syndrome that is designed even as dermatoporosis comprise morphological markers of fragility--rather trivial--such as senile purpura, stellate pseudoscars and skin atrophy, and functional expression of skin fragility resulting from minor traumas such as frequent skin laceration, delayed wound healing, nonhealing atrophic ulcers and subcutaneous bleeding with the formation of dissecting hematomas leading to large zones of necrosis. She can never stay at the sun rays, even in winter and has to use always total block screen emulsions, and the most important manifestation of the syndrome is under her eyes and onto cheekbones.

2) one old woman (75 y.old) presenting so dry and chapped lips that no lipstick or rouge can adhere onto the buccal mucosa.

3) one child with milia under eyes and eyelids (the measures by ballistometer were carried out only after the third day of application of Ceratum)

4) one middle age woman suffering from the Rombo's syndrome.It s a very rare genetic disorder characterized mainly by atrophoderma vermiculatumof the face, multiple milia, telangiectases, acral erythema peripheral vasodilation with cyanosis (12) and a propensity to develop basal cell carcinomas(13) The lesions become 
The revival of an ancestral galenic preparation called "Ceratum" apt to re-establish the normal ..

visible in late childhood, began at ages 7 to 10 years and are most pronounced on the face, At that time a pronounced, somewhat cyanotic redness of the lips and hands was evident as well as moderate follicular atrophy of the skin on the cheeks. In adulthood, whitish-yellow, milia-like papules and telangiectatic vessels developed. The papules were present particularly on the cheeksa and forehead, gradually becoming very conspicuous and dominating the clinical picture. Trichoepitheliomas were found in 1 case. In adults, the eyelashes and eyebrows were either missing or irregularly distributed with defective and maldirected growth. Basal cell carcinomas were a frequent complication. The skin atrophy was referred to as vermiculata atrophoderma. Basal cell carcinomas may develop around the age of 35 . Histological observations during the early stage include irregularly distributed and atrophic hair follicles, milia, dilated dermal vessels, lack of elastin or elastin in clumps. As in the precedent case the measures using the ballistometer were performed only afyter the third day of application of the Ceratum.

The Ballistometer is an instrument designed to evaluate in vivo, in a non- invasive manner, the viscoelastic properties of the skin by analyzing the bounce pattern of a pendulum- like probe as it impacts on the skin. The kinetic energy of the probe striking the skin is stored by the elastic components of the skin and is then released, causing the probe to rebound. Since the skin is a viscoelastic, anisotropic material, the height of the probe rebound is influenced by the amount of stored energy lost in the viscosity of the skin. In this manner, the Ballistometer measures the capacity of the skin to absorb mechanical energy, and it assesses mostly the behavior of the tissues underlying the stratum corneum.

Results are graphically represented by a curve where several factors are responsible of the final values (recorded as coefficient of restitution) that range from 0 to $1 \mathrm{~mm}$.

The aforesaid factors correspond to

a) Indentation: the peak penetration depth of the probe tip beneath the skin level (skin datum)

$\beta) \mathrm{K}$ : the start height of the probe tip above the skin surface. This is directly related to the energy stored in the torsion wire $\gamma$ Alpha: the rate of energy damping. Large values indicate energy absorbent (in-elastic) samples

8) ) Coefficient of Restitution - CoR: a high value indicates a highly elastic sample

ع) ) Area: the area between the bounce profile and the skin zero datum

The curve is represented like the following, where it is possible to observe that the real values go from 0 and $1 \mathrm{~mm}$.

Here follows a graphical example of a curve obtained by using a torsional ballistometer.

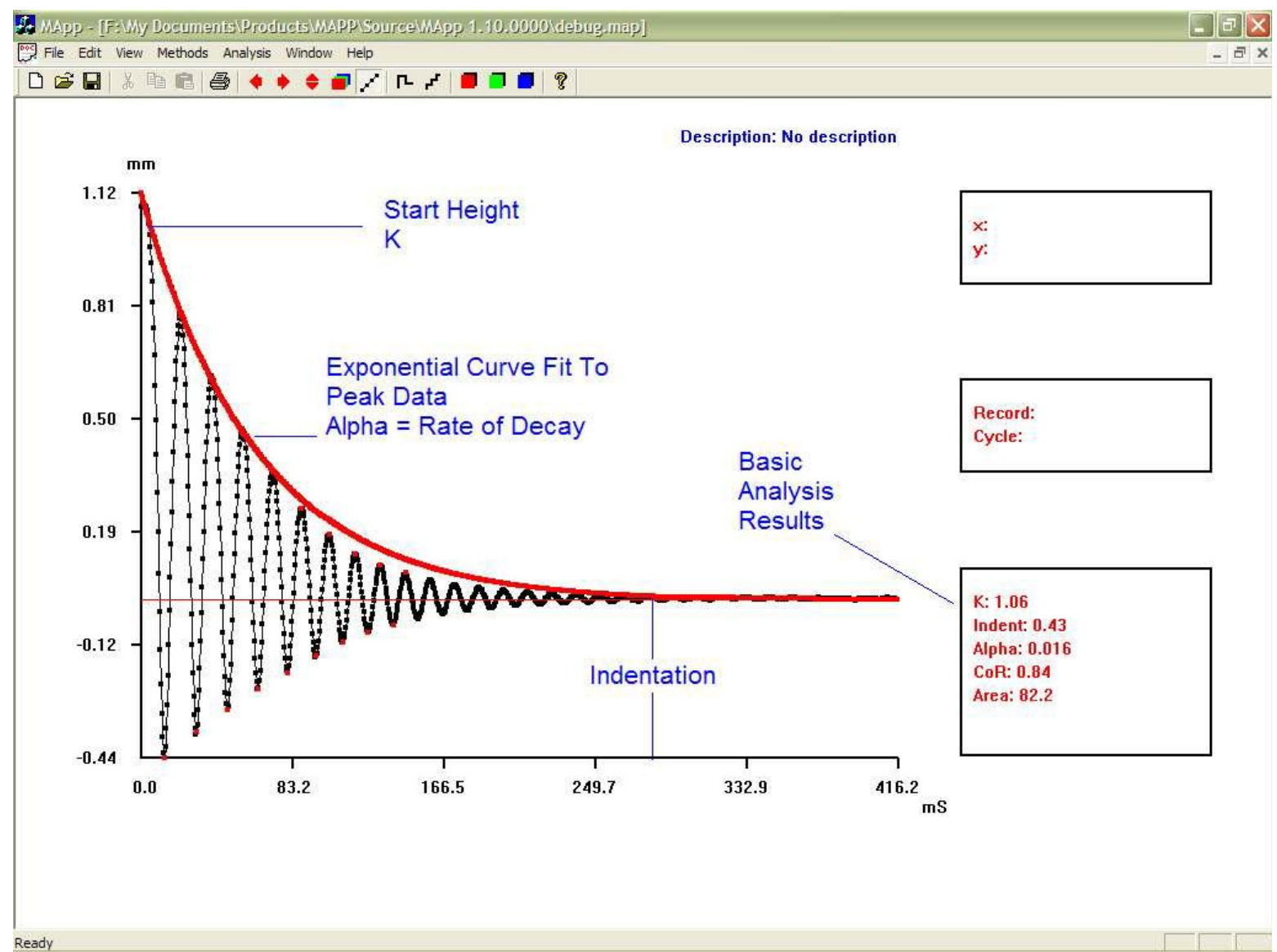


These values are derived form the heights of the first and second rebounds, measured as the amplitude of the angular displacement of the probe. The heights of the first and second rebounds correlate directly with the elasticity of the skin, in that a more elastic material yields a higher bounce when struck by the probe than a less elastic material, assuming equivalent viscosity (Fthenakis, et al. 1991). While these variables are commonly considered indicators of the elastic nature of the skin, the amplitude and/or number of displacements of the probe can convey other qualities, such as the firmness or softness of the skin (Jemec et al. 2001). The coefficient of restitution relates to the proportion of the maximum height that the probe rebounds after striking the skin. The coefficient of restitution can range from 0 , if the impact was completely devoid of elasticity, to 1 , which is a theoretical state of complete elasticity (Fthenakis, et al. 1991).

In Table I one can notice that the values recorded after measure by wire torsion using the ballistometer tend all to increase (Case 3 and 4, obviously, as aforesaid, only after the third day).

\section{Table I:}

\begin{tabular}{|l|l|l|l|l|l|l|l|l|l|l|}
\hline Case & $\begin{array}{l}\text { Co-R at } \\
\text { 1st day }\end{array}$ & $\begin{array}{l}\text { Co-R at } \\
\text { 2nd day }\end{array}$ & $\begin{array}{l}\text { Co-R at } \\
\text { 3rd day }\end{array}$ & $\begin{array}{l}\text { Co-R at } \\
\text { 4th day }\end{array}$ & $\begin{array}{l}\text { Co-R at } \\
\text { 5th day }\end{array}$ & $\begin{array}{l}\text { Co-R at } \\
\text { 6th day }\end{array}$ & $\begin{array}{l}\text { Co-R at } \\
\text { 7th day }\end{array}$ & $\begin{array}{l}\text { Co-R at } \\
\text { 7th day }\end{array}$ & $\begin{array}{l}\text { Co-R at } \\
\text { 8th day }\end{array}$ & $\begin{array}{l}\text { Co-R at } \\
\text { 9th day }\end{array}$ \\
\hline 1 & 0.01 & 0.03 & 0.09 & 0.44 & 0.58 & 0.69 & 0.78 & 0.82 & 0.81 & 0.93 \\
\hline 2 & 0.07 & 0.09 & 0.11 & 0.15 & 0.36 & 0.54 & 0.64 & 0.79 & 0.89 & 0.97 \\
\hline 3 & $/ / / /$ & $/ / /$ & //I & 0.25 & 0.44 & 0.56 & 0.66 & 0.71 & 0.88 & 1.01 \\
\hline 4 & $/ / /$ & /II & $/ / /$ & 0.11 & 0.44 & 0.64 & 0.79 & 0.85 & 0.89 & 1.0 \\
\hline
\end{tabular}

\section{Discussions}

No statistical results can be calculated at all, since the measures of two of the four cases begin only at the 4th day. It is suggestive to notice anyway that in all the cases an excellent regrowth of the original Co-R (in $\mathrm{mm}$ ) is valuable. The recovery of the viscoelasticity of the dermal component and the hydration of the stratum corneum are well established.

\section{References}

[1]. Hermanns-Lê T, Hermanns JF, Lesuisse M, Piérard GE: Cyclic Catamenial Dermatoses;Biomed Res Int. 2013 ; 15 (64) 59.

[2]. Brasad P: Principles and Practice of Medicine a TB for Students and Practitioners. Jaypee Brothers Publishers.1997.Calcutta

[3]. 3)Berk DR, Bayliss SJ. Milia: a review and classification. J Am Acad Dermatol. 2008 Dec. 59(6):1050-63.

[4]. Sachdeva M, Kaur S, Nagpal M, Dewan SP. Cutaneous lesions in new born. Indian J Dermatol Venereol Leprol. 2002 Nov-Dec. 68(6):334-7.

[5]. Langley RG, Walsh NM, Ross JB. Multiple eruptive milia: report of a case, review of the literature, and a classification. $J$ Am Acad Dermatol. 1997 Aug. 37(2 Pt 2):353-6.

[6]. Southwick GJ, Schwartz RA. The basal cell nevus syndrome: disasters occurring among a series of 36 patients. Cancer. 1979 Dec. 44(6):2294-305.

[7]. Michaelsson G, Olsson E, Westermark P. The Rombo syndrome: a familial disorder with vermiculate atrophoderma, milia, hypotrichosis, trichoepitheliomas, basal cell carcinomas and peripheral vasodilation with cyanosis. Acta Derm Venereol. 1981. 61(6):497-503

[8]. Rasmussen JE. A syndrome of trichoepitheliomas, milia, and cylindromas. Arch Dermatol. 1975 May. 111(5):610-4.

[9]. Su WP, Chun SI, Hammond DE, Gordon H. Pachyonychia congenita: a clinical study of 12 cases and review of the literature. Pediatr Dermatol. 1990 Mar. 7(1):33-8.

[10]. Bergman R, Schein-Goldshmid R, Hochberg Z, Ben-Izhak O, Sprecher E. The alopecias associated with vitamin D-dependent rickets type IIA and with hairless gene mutations: a comparative clinical, histologic, and immunohistochemical study. Arch Dermatol. 2005 Mar. 141(3):343-51.

[11]. Tsuji T, Kadoya A, Tanaka R, Kono T, Hamada T. Milia induced by corticosteroids. Arch Dermatol. 1986 Feb. 122(2):139-40. .

[12]. van Steensel MA, Jaspers NG, Steijlen PM: "A case of Rombo syndrome". Br. J. Dermatol.:2001; 144 (6): 1215-8

[13]. Epstein W, Klingman AM. The pathogenesis of milia and benign tumors of the skin. J Invest Dermatol. 1956 Jan. 26(1):1-11. 